\title{
Reflexões sobre ensino- aprendizagem em teatro na educação de jovens e adultos (EJA)
}

\author{
A na C arolina M uller Fuchs* \\ C armem Silvia Soares da Silva** \\ Lisinei Fátima Dieguez R odrigues** \\ $\mathrm{M}$ arcelo K ozorosky A Imei da***
}

\begin{abstract}
R esumo: D iante do desafio de pensar uma proposta curricular para o ensino-aprendizagem em Teatro por adultosquenão visam à profissionalização nessa arte, o grupo de docentes que assina este artigo traçou reflexões que abordam seus referenciais teóricos, suas propostas metodológicas e apresenta também al guns breves relatos de experiências ocorridas no ambiente escolar. O bservações empíricas bem como falas da literatura especializada são pontuadas ao longo do texto. O bjetiva-se ampliar a ideia da aula de Teatro como uma prática em educação condizente com os tempos e espaços de adultos e jovens reincluídos no contexto escolar.
\end{abstract}

Palavras-C have: Teatro-educação, Teatro na maturidade, Teatro para adultos não-profissionais.

* M estre em Educação pela UFRGS. Bacharel em Educação Artística - habilitação em Artes Cênicas pela UFRGS. E-mail: ana_fuchs@ig.com.br

* Professora de Teatro do CAp/UFRGS. E-mail: carmencaca@yahoo.com.br

*** Especialista em Educação Profissional Técnica de N ível M édio Integrada ao Ensino M édio na M odalidade de Educação de J ovens e Adultos, pela Faculdade de Educação da U FR GS. Bacharel em Arte Cênicas - habilitação Interpretação Teatral e Licenciada em Educação Artística - habilitação em Artes Cênicas, pela UFRGS. E-mail: lisinei@ cap.ufrgs.br

**** M estrando em Educação pela U FR GS. Bacharel em Arte Cênicas - habilitação Interpretação Teatral e Licenciado em Educação Artística - habilitação em Artes Cênicas pela UFRGS. E-mail: almeidamarc@yahoo.com.br 


\begin{abstract}
A bstract: I $n$ face of a challenge to think in a curricular propose to teach learn theater for adults that don't want to be a professional in this art, the teaching staff that signs this research traced reflections to approach your theoretical references, your methodological proposes and present some short reports about experiences on a school surrounding. Empiric observations and extracts from specialized literature are punctuated in this text. Theobjective is to amplify the idea of theater lessons as a practice in an education that goes with time and space of young and adults recredited on a school context.
\end{abstract}

Keywords: Teaching theater, Theater on maturity, Theater for unprofessional adults.

\title{
Introdução
}

As reflexões que compõem este artigo desafiam os educadores a refletir acerca da possibilidade da experiência teatral no contexto escolar da E ducação de J ovens e Adultos (EJA). As vivências teóricas e práticas nos processos de ensino-aprendizagem para alunos que não têm como objetivo a profissionalização ${ }^{1}$ na arte da representação teatral são o ponto de partida para os educadores que procuram lançar luzes a um caminho propositivo de inserção da área de conhecimento Teatro nas bases curriculares dos cursos de EJA. Sendo a oferta de educação em Arte obrigatória para as instituições e facultativa para os educandos, torna-se necessário esclarecer a abrangência que o estudo do Teatro pode alcançar. 0 principal objetivo desta reflexão é ampliar a idéia da aula de Tea tro não somente como atividade socializante e recreativa, mas como uma prática em educação estética e ética, condizente com os tempos e espaços desses adultos ejovens reincluídos no contexto escolar.

1 A questão da não-profissionalização é enfatizada neste artigo porque implica uma abordagem diferenciada da pedagogia teatral quanto a seus objetivos, técnicas e métodos. 


\section{Teatro na escola e o aluno-ator adulto}

Inicia-se esta reflexão apontando a posição explícita dos documentos oficiais em relação ao ensino de Arte na modalidade EJA. N o Parecer do CN E/CEB 11/2000 - Diretrizes Curriculares $\mathrm{N}$ acionais para Educação de Jovens e A dultos - elaborado pelo relator Carlos Roberto Jamil Cury, a educação em arte aparece com a recomendação de caráter facultativo ao aluno.

O s componentes curriculares ligados à Educação Artística e Educação Física são espaços oportunos, conquanto associados ao caráter multidisciplinar dos componentes curriculares, para se trabalhar a desinibição, a baixa auto-estima, a consciência corporal e o cultivo da socialidade. D esenvolvidos como práticas sócio-culturais ligadas às dimensões estética e ética do aluno, estes componentes curriculares são constituintes da proposta pedagógica de oferta obrigatória e freqüência facultativa. Contudo a oferta destes componentes não será obrigatória para os alunos no caso dos exames supletivos avulsos descolados de unidades educacionais que ofereçam cursos presenciais e com avaliação em processo (CURY, 2000, p. 63-64).

Primeiramente é necessário que se estabeleçam as distinções entre a EJA e a escolarização em tempo regular. Tendo claro essas particularidades, as características de aprendizagem, os processos e o tempo desses alunos, pode-se então pensar como a intervenção teatral torna-se um diferencial para estes sujeitos. Parece necessário então defender o fazer teatral na escola aos alunos de EJA como disciplina que possibilita construir conhecimentos significativos para o desenvolvimento do sujeito, tanto no que se refere às estruturas cognitivas quanto a conteúdos específicos.

É comum, por parte dos alunos, questionamentos como: "Professor, por que temos de ter aula de teatro se eu não quero ser ator e não cai no vestibular?" I sto faz pensar no quanto se é necessário um esclarecimento, tanto para alunos e colegas professores como para os pais, no caso das crianças e adolescentes, sobre a real importância do ensino de teatro na escola. 
U sualmente costuma-se associar/justificar a necessidade da prática teatral com o "benefício" da desinibição ("é ótimo para a pessoa aprender a falar em público"). É verdade que o teatro ajuda nesse sentido, mas isso parece pouco para justificar sua presença como parte importante na educação do sujeito. Então, retorna a questão: qual a necessidade do ensino de teatro? Qual o conhecimento específico que somente ali se pode construir, e que é essencial para nosso desenvolvimento como seres humanos?

0 teatro como forma, como linguagem artística, exige tanto de alunos como de atores a compreensão do espaço, do tempo, do movimento, do jogo individual e coletivo e das convenções cênicas para a efetiva estruturação do ato teatral. A forma teatral é o próprio conteúdo antes mesmo de eleger qualquer conceito para ser abordado em cena. 0 teatro, então emerge como disciplina fundamental no contexto escolar pela sua forma e pelas inúmeras possibilidades de elaboração de conceitos. Q uando determinado conceito é abordado de forma teatral ele é organizado a partir de movimentos, textos, imagens, sons, jogos, intenções, sensações, entre outros, tornando cada vez mais complexos e amplos os seus significados.

O prazer de colocar-se diante de uma platéia pode ser traduzido como a satisfação de perceber-se um autor que, em comunhão com os demais atores-autores em cena, promove comunicação e empatia com os leitores-espectadores da platéia.

O teatro, então, torna-se instrumento de ressignificação social, de construção de identidade individual e coletiva, a partir do momento que propicia reflexões e novos olhares a respeito do espaço e dos acontecimentos que os cercam, dessa forma o teatro torna-se disciplina fundamental nas propostas curriculares de EJA.

E nesse resgate da relação estética do sujeito com o meio, altera-se a função pragmática da arte na escola, para muito além das participações nos eventos comemorativos, para além da desinibição, dos aspectos recreativos ou socializantes, o que leva a questionar o caráter atribuído ao ensino de Arte no parecer do CNE/CEB 11/2000 citado anteriormente. 
Percebemos em nossa sociedade contemporânea uma valorização excessiva da relação prática do homem com o mundo (que gira em torno de uma ideia de funcionalidade objetiva das coisas) em detrimento de sua relação estética (centrada na sensibilidade do sujeito). Como consequência disso, vemosum empobrecimento de referências estéticas e éticas, bem como de um sentido de beleza, que fica limitado ao aspecto exterior de um ser ou de um objeto.

A lém disso, criou-se uma apologia do sucesso individual, da celebridade, "dos quinze minutos de fama", em que o mais importante é destacar-se, não importa a que preço, e o espaço da exposição diante de uma plateia acaba se tornando mais um meio para esse fim. Partindo dessa perspectiva, questões éticas ficam em segundo lugar, e a figura do outro é ignorada. Intervenções pedagógicas para retomar a educação do sensível, mais do que o treinamento em técnicas de expressão ou a elaboração de produtos artísticos para a exposição mercadológica da instituição de ensino, podem alterar esse processo.

Sob vários aspectos a experiência teatral envolve 0 alunoator em um movimento inverso a este, a começar pela principal característica do acontecimento teatral: a presença viva do ator e do espectador no local da representação. D esde seu surgimento na Grécia antiga, o teatro éum momento de encontro e de comunhão entre atores e plateia.

O Teatro também é exercício de alteridade. Ao colocar-se no lugar de personagens que vivem experiências diversas da sua, o aluno-ator amplia sua capacidade de "pôr-se no lugar do outro", de perceber os fatos sob outra perspectiva além da sua. E esse tipo de experiência propicia reflexos em seu comportamento social.

U ma relação exclusivamente utilitária do indivíduo com seu meio social pode gerar o empobrecimento da experiência e da criação, numa apologia do previsível. Sem perceber imediatamente qual a serventia de uma determinada experiência tende-se a deixar de experimentar, e assim deixa-se de construir o novo. $\mathrm{N}$ ada de arriscar-se no desconhecido buscando desvelar o novo. 
Do mesmo modo, aspectos essenciais da vida humana, como o lúdico, o estético e o poético são vistos por muitos como "supérfluos" ou desnecessários, uma vez que se acredita que o homem poderia sobreviver sem eles. M esmo que não dissessem respeito à sobrevivência do homem, estão relacionados à sua qualidade de vida: uma relação estética pouco desenvolvida conduz a uma percepção reducionista e a uma crescente crueza na relação do homem com seus semelhantes e com o mundo em que vive. M ostra disso são as diversas situações de violência social que perpassam diferentes culturas e situações sócio-econômicas, presentes inclusive no contexto escolar.

A realidade efetivamente encontrada nas instituições escolares brasileiras ainda é o cumprimento das exigências legais mínimas no que tange a oferta de ensino em Arte. A pesar dos documentos oficiais brasileiros já estabelecerem a importância de educar em Arte respeitando-se a divisão nas especialidades de Educação M usical, Artes V isuais, D ança e Teatro, os tempos de trabalho, os espaços adequados e os docentes especialistas para a organização das situações de aprendizagem dessa forma ainda são escassos na maioria das escolas brasileiras.

É comum encontrar alunos recém ingressos nos cursos de EJA questionarem a validade das aulas de Arte, tendo em vista que, nos relatos empiricamente observados, há a manifestação da memória da aula de "artes" como a reprodução de técnicas para a elaboração de produtos artísticos.

A inda de forma empírica é possível especular que o teatro na EJA possa oferecer ao jovem e adulto o que já foi observado nas aulas de teatro para adultos na maturidade² (alunos a partir de 50 anos de idade). Os participantes chegam para a experiência

2 É este o objetivo da A ção de Extensão "Fazendo Teatro na M aturidade" que acontece no Colégio de A plicação (CAp) uma vez por semana: Propiciar aulas de Teatro para que o grupo desenvolva a consciência corporal, o pensamento imaginativo, a criatividade e o espírito crítico através da prática de exercícios teatrais e improvisações, culminando com a montagem de uma peça teatral. As aulas semanais acontecem com duração de 1 h e 30 minutos na sala do teatro do Colégio, com o seguinte desenvolvimento: Aquecimento/conscientização corporal, exercícios e jogos teatrais, improvisações e montagem de peça teatral para ser apresentada para a comunidade. 
teatral desacreditando-se, sentindo-se incapazes de colaborar para 0 enriquecimento do grupo. Eles colocam que vem em busca "de algo". Traduz-se essa busca pelos objetivos de conhecer melhor o seu próprio corpo e descobrir como lidar com ele em um espaço diferente do espaço cotidiano - o espaço cênico descobrindo suas possibilidades de interação com o outro (colega ou platéia) através do seu corpo e voz, compondo figurinos, cenários, sonoridades, enfim vivenciando as oportunidades de uma experiência teatral. Com a continuidade das vivências em jogos teatrais e exercícios, os alunos se mostram mais confiantes na importância de suas contribuições para o grupo e no uso do seu potencial para a resolução das propostas de aula. J ogar, improvisar, criar cenas, pensar juntos, escutar o outro, experimentar, avaliar, ajustar, polir... É possível discorrer longamente sobre a importância da criação coletiva nas aulas de teatro.

0 teatro possibilita entre outras inúmeras coisas que 0 grupo perceba-se capaz, ou mais capaz ainda, à medida que age como grupo, analisando a sua própria vivência, valorizando-a e a transformando, se assim quiser.

Tanto a descoberta do sentido de grupo quanto da capacidade de criação, própria e coletiva, e de valorização do que foi criado possibilita ao indivíduo transcender a perspectiva egocêntrica. Perceber o grupo concomitante ao processo de valorização de sua autoria aparece como uma "atitude de resistência" a um mundo que insiste em nos dizer que poderemos ser facilmente substituídos e que banaliza a todo instante a vida e as relações interpessoais.

0 envolvimento com a criação pessoal leva-nos à esfera da criação única, especial porque não pode ser repetida por outro. Como exemplo, dois atores podem interpretar a mesma personagem, com o mesmo texto e sob a mesma direção, e ainda assim resultarão dois trabal hos distintos, pois a composição de personagens depende também de condições pessoais (técnicas, físicas e emocionais) de cada ator.

O utra observação empírica aponta que o processo de criação de cenas, a partir das improvisações, as "costuras" entre uma 
e outra são demorada e necessitam de muita dedicação e paciência. No caso de alunos-adultos observa-se que esse processo tende a ser tranqüilo e fluente, o que pode ser atribuído à estruturação do pensamento adulto no qual o indivíduo já pode contemplar o ponto de vista do outro. Faz parte desse processo a criação de trilha sonora, figurinos, objetos cênicose cenário, enfim elementos que cercam e compõem a linguagem teatral. N esse momento 0 fato de estar trabalhando com adultos faz toda a diferença para o docente em Teatro habituado a organizar o teatro escolar. 0 grupo se envolve em todas as etapas do trabalho assumindo e dividindo as tarefas ${ }^{3}$ como comprar tecidos, costurar, fazer acessórios, construir cenários ou panos de fundo para as apresentações em locais abertos. Para isso o grupo consegue se autossustentar, angariando fundos, organizando e gerenciando ações como rifas ou participação em eventos.

Portanto considerarmos que oferecer a disciplina de Teatro na EJA, mas ao mesmo tempo deixar a freqüência facultativa, é enterrar essa possibilidade de vivência no grupo antes mesmo que possa se constituir. 0 trabalho do grupo no teatro é de processo, tão complexo e necessário, que define e caracteriza a própria arte teatral. $\mathrm{N}$ ão há processo nem produto teatral se não houver interação no grupo de trabalho. E pensando na situação prática de sala de aula, é preciso saber com quem contar, aula a aula, senão não existe maneira de se constituir essa interação. Parece óbvio afirmar isto, mas é bem difícil avançar nos métodos de educação pelo Teatro quando se trabalha com um grupo de freqüência inconstante.

\section{Desenvolvimento cognitivo do jovem e adulto}

A credita-se que o processo de aprendizagem de um jovem ou adulto se difere em relação ao processo de uma criança no que

3 O utro aspecto observado junto ao grupo do projeto de extensão "Teatro na M aturidade". 
se referem, principalmente, as estruturas cognitivas. A maioria dos adultos já tem desenvolvidas estruturas cognitivas que na criança ainda estão em formação. Então, mesmo que ele tenha condutas aparentemente sensório-motoras, simbólicas ou opera tório-concretas, sua mente pode estar processando as novas informações com base em uma estrutura formal que lhe permite assimilar os novos conteúdos de outra maneira. É preciso lembrar que nem todo adulto está no estágio formal de desenvolvimento cognitivo e, mesmo que já possua estruturas que apóiam o pensamento formal, pode apresentar dificuldades em alguns conteúdos em virtude de não ter desenvolvido esquemas que lhe permitam operar em determinadas áreas, conteúdos ou situações. M as, enfim, essas características em relação às estruturas cognitivas de um adulto fazem pensar que o mesmo, provavelmente, terá um tempo diferenciado de aprendizagem, justamente porque se apóia em estruturas mais complexas.

Percebe-se que as expressões verbais acerca dos processos e produtos artísticos gerados nas aulas de Teatro para adultos aparecem com detalhamento e de forma mais rápida do que nas crianças, onde o foco da atenção está centrado no fazer, no jogo propriamente dito. ${ }^{4}$ É comum que 0 adulto produza reflexões e as expresse de forma espontânea para professor ou colegas.

Se considerarmos como característica do período de operações formais, a expressão de hipóteses raciocinadas sem a presença de meios concretos, melhor dizendo, as inferências distantes do observável aproximam-se ainda mais as práticas teatrais ao desenvolvimento do pensamento simbólico.

Teatro, arte efêmera, que transforma a todo instante tempo, espaço e ações, operando na cumplicidade com o público, exige dos alunos-atores e da sua platéia constante exercício de uma imaginação que se apóia numa lógica pré-existente, em referências comuns. Exemplificando: para um grupo de alunos-atores de EJA Ensino Médio $^{5}$ foi proposto o seguinte jogo: mostrem

4 O bservação registrada em anotações do professor durante aulas com adultos do então chamado "Curso Supletivo", N ova Petrópolis, 1998.

5 Em 2007, numa parceria entre o Colégio de A plicação e a Escola Técnica da U FR GS, iniciou o curso de Ensino Médio na modalidade. 
através da ação de seus corpos que estão em um posto de combustíveis. Sem a necessidade de uma combinação prévia, os participantes passaram a ocupar o espaço em ações que foram vistas em algum momento dos seus cotidianos. Eles delimitaram o local da bomba de gasolina, o tamanho do carro hipotético, agindo para sua limpeza e abastecimento, o local de espera e o caixa/escritório. O s que não se ocuparam diretamente com o carro compuseram figuras desse ambiente. 0 "bonecão" de propaganda, os demais frentistas e os clientes que aguardavam na fila. Toda essa construção, tanto do espaço hipotético como das relações de cena, foi concebida sem um modelo concreto (foto ou observação recente). A comunicação não-verbal, a memória, a confiança no grupo foram exercitados durante o jogo. A pós, como é costume nas aulas de Teatro, procedeu-se uma conversa avaliativa acerca dos resultados vistos: proporção dos objetos, verossimilhança (semelhança com a realidade), adequação dos tempos e espaços cotidianos para o que fica mais adequado à linguagem teatral propriamente dita. Essa atividade possibilitou uma leitura e representação de um fragmento da realidade de forma coletiva, dialogada. Salienta-se ainda que desafios propostos e resolvidos em grupo, prática constante nas aulas de Teatro, aparecem como fa tores que incentivam a cooperação, a reflexão em grupo, o deslocamento do próprio ponto de vista em prol do bem coletivo. Conduta desejada e fomentada tradicionalmente através do discurso.

O s valores essenciais em educação não se prestam a uma vivência quando transmitidos em forma de discursos; porque o conhecimento ea compreensão da realidade são mais facilmente alcançados pela vivência que pela informação (ANTUNES, 1998, p. 75).

N esse contexto, o teatro emerge como elemento importante para a formação do sujeito. 0 desafio do fazer teatral é articular e coordenar rapidamente no momento da cena os vários elementos, atores, público, ações, espaço, tempo. Essa composição está em constante transformação no jogo cênico, possibilitando e construindo a criação de forma coletiva, espontânea e envolvente. 0 teatro é uma arte que se faz na presença do outro, 
com um colega de cena e/ou para o público que assiste, o que o torna o jogo ainda mais desafiador e instigante. Jogar sozinho, em função das próprias ações e relações com espaço, objeto, tempo, significa trabalhar a partir de um ponto de vista. Q uando o jogo envolve mais pessoas, envolve as relações que cada indivíduo tem com a linguagem teatral e com o mundo que o cerca. É nesse aspecto que a complexidade do ato de improvisar se faz presente no âmbito das relações humanas e encontra-se com a própria natureza do fazer teatral.

M as na verdade o teatro tem o potencial - inexistente em outras formas de arte - de substituir um ponto de vista único por uma pluralidade de visões diferentes. $O$ teatro pode apresentar um mundo em várias dimensões ao mesmo tempo (...) (BROOK, 1995, p. 34).

Piaget (1998, p. 187) aborda especificamente a questão das práticas artísticas no que se refere ao desenvolvimento do sujeito. Para o autor, a criança pequena em relação aos mais velhos é mais criativa e espontânea, pois "consegue exteriorizar espontaneamente sua personalidade e suas experiências interindividuais graças aos diversos meios de expressão à sua disposição". A educação artística tem como base dois pólos: o que é vivido pelo "eu", as inqui etações e desejos que encontram no jogo simbólico uma forma de expressão individual, e a realidade material e social que exige instrumentos, meios de comunicação e expressão coletivos. 0 artista tem a função de construir objetivamente o que há no plano subjetivo, ou ainda, exteriorizar, construir o elo entre mundo interior e exterior. 0 problema da educação artística, em especial do Teatro, é que o meio social impõe determinados comportamentos que acabam por inibir as ações espontâneas do sujeito. As crianças mais velhas e até mesmo os adultos tendem a conter seus impulsos criativos. Suas ações e seu comportamento seguem condutas e valores sociais que condicionam sua maneira de agir e, conseqüentemente, limitam o desenvolvimento da expressividade e criatividade. Essa situação aponta para duas grandes reflexões: a questão do grupo como elemento que apóia e dá segurança ao indivíduo ao mesmo tempo em que exige uma participação 
ativa e eficaz para a realização de suas atividades e o reflexo da presença do professor orientador, que causa uma expectativa por parte do aluno-ator em relação ao seu trabalho.

A espontaneidade e a criatividade são condutas desejáveis num ambiente de aprendizagem e se estruturam, se desenvolvem a partir de um ambiente de liberdade. É necessário se construir uma atmosfera de trabal ho baseada na segurança e confiança. Spolin (1987) enfatiza que a primeira condição para jogar é ter "liberdade pessoal", para que o aluno-ator possa realmente se envolver com a realidade que o cerca, livre de qualquer constrangimento ou coação.

Q uando o ator constrói seu trabalho a partir de seu interesse e sua forma de agir e não apenas repete comportamentos já estabelecidos, ele se apropria da linguagem teatral e abre espaço para a construção da sua identidade como artista. Faz-se sujeito, único, diferente, capaz de criar e trocar com outros indivíduos. "A espontaneidade pedeque entremos num território desconhecido - nós mesmos!" (SPO LIN , 2001, p. 27).

$\mathrm{N}$ a mesma medida em que 0 ator se desenvolve, o grupo também cresce, pois são nas diferenças que residem os elementos de troca capazes de construir o novo. 0 fazer teatral, então, torna-se um jogo prazeroso e mais um instrumento de expressão e comunicação do aluno-ator e do grupo. 0 jogo flui, porque há elementos para seu desenvolvimento e porque os sujeitos compreendem e coordenam as diversas perspectivas envolvidas. A espontaneidade e criatividade são, portanto, elementos que se constroem na relação direta do sujeito com o meio, produto de um processo de descentração do sujeito em relação ao universo que o cerca e às pessoas que compõem seu universo social.

As intervenções pedagógicas em Teatro praticadas no Colégio de A plicação, nas atividades de ensino, de pesquisa ou de extensão, levam em conta o perfil dos sujeitos da aprendizagem quanto ao seu desenvolvimento cognitivo, suas intencionalidades, faixa etária e entorno cultural. 


\section{Intencionalidades quanto ao fazer teatral}

As intenções dos sujeitos que freqüentam as aulas de Teatro nas escolas partem, a priori, do cumprimento de uma exigência curricular. D e acordo com as propostas metodológicas apresentadas, as características individuais desses sujeitos e os resultados obtidos na convivência grupal, é possível observar um maior envolvimento e valorização da disciplina ou não. A experiência na docência em Teatro mostra como é comum essa reação quando se inicia o uso da linguagem Teatral.

O bserva-se, ainda, que de forma empírica, que as crianças e jovens trazem uma disposição física maior para o uso do espaço cênico, entretanto, a habilidade em organizar-se para o trabaIho coletivo, trazida pelo adulto, contribui de forma decisiva para uma produção artística significativa nos espaços escolares.

Independente da faixa etária, as intencionalidades dos alunos-atores no fazer teatral revelam seus conteúdos sócio-afetivos e de cognição. Suas concepções éticas (o que é bom ou ruim) e estéticas (o que é belo ou é feio) aparecem na forma como se articulam no jogo ou nos momentos em que é necessário improvisar suas ações.

A experiência com adultos no curso de extensão "Teatro na M aturidade" incita algumas reflexões quanto ao uso do espaço do fazer teatral por pessoas que retornam a um ambiente de aprendizagem. Alguns adultos na faixa etária de 50 anos ou mais, trabalhadores, ou já em fase de aposentadoria, guardam ainda um grande desejo de fazer teatro, o que não foi possível fazer quando jovens, ou na fase adulta, por necessitarem priorizar trabalho, família, filhos. Por que não agora, na maturidade, quando parece que a rotina já está mais organizada permitir-se a vivência nessa linguagem artística? 0 aluno de teatro na maturidade chega mostrando muita vontade de atuar, como um desejo guardado, parecendo ser, por vezes, maior do queo demonstrado pelos adolescentes e crianças. A fase adulta traz ao sujeito a idéia de que o produto final precisa ser "bem acabado", essa noção estética é muito 
importante no fazer teatral. Antes de o grupo atingir seu objetivo inicial maior, a montagem de uma peça, ele passa por muitos encontros, partindo do jogo teatral proposto no método de Spolin (1987).

\section{Faixa etária e diferentes características no fazer teatral}

O princípio básico do Jogo Teatral define que o corpo torna-se disponível para experimentar todas as propostas desde que exista um espaço propício para uma experiência criativa o que leva 0 aluno a experimentar estados e situações diferentes do seu cotidiano.

Como espaço propício, pode-se entender que as temáticas abordadas pelos sujeitos, a forma como se organizam no espaço, o grau de autonomia revelado em cada etapa da aula e a linguagem utilizada pelo educador nas orientações ao grupo irá variar no sentido de aproximar o aluno com a proposta da aula. Os conteúdos da área de Teatro pouco variam a cada grupo etário de alunos-atores, entretanto os resultados obtidos são bem distintos.

O s usos dos tempos e espaços e o corpo do indivíduo em estado de representação são a matéria-prima para qualquer aula de Teatro, independendo da idade dos sujeitos. 0 fazer teatral pelo jogo mostra-se interessante para a educação em Teatro em qualquer faixa etária, pois considera as diferentes estruturas cognitivas e, por conseqüência, a articulação do sujeito com o pensamento simbólico. Os alunos da maioridade, por exemplo, manifestam necessidade de atenção, acompanhamento e aprovação por parte do professor e do grupo, por vezes até maior do que os alunos da educação básica, adolescentes e crianças.

Como método de construção do fazer teatral que abrange do jogo ao espetáculo, Spolin (1987) estabelece algumas regras: o foco, que é ponto de concentração (POC) do jogo, aparececomo 
o principal objetivo do jogador. Os desafios são progressivos envolvendo o estabelecimento de circunstâncias propostas, como "onde" (lugar em que vai se passar a cena), "quem" (personagens envolvidas), "o que" (a ação, os acontecimentos) - (Spolin, 1987, p. 20-21, 81-82). Através desse método, detalhadamente exposto ao longo de sua obra, a autora propõe estratégias de ensino para - Teatro que contemplam diferentes faixas etárias.

$\mathrm{N}$ as improvisações os atores experimentam personagens, ações físicas e a ação dramática. $\mathrm{Na}$ experiência do teatro na maturidade, o grupo parte de um roteiro baseado em um texto, conto, crônica ou outro, que é adaptado para o teatro. D efinido o que será montado, o processo de criação das cenas foca seu trabalho na elaboração das ações físicas. É desafiador para os atores criarem movimentos, deslocamentos e ações que se mostrem eficazes com o que querem representar. Parece natural para alguns alunos narrar os acontecimentos e permanecerem estáticos, o que não é bom para a cena teatral.

No momento de o grupo combinar as improvisações, que serão transformadas em cena para formar a peça, partindo do pressuposto que o corpo fala, não precisamos "contar", mas sim "mostrar" aquilo que queremos dividir com a plateia. É necessário trabalhar com os alunos-atores a idéia de que em cena, mais do que falar, é preciso agir.

É o que Stanislavski (1970) conceituou como ações físicas. Stanislavski começou a desenvolver suas técnicas no começo do século XX e, no princípio, ele enfatizava os aspectos interiores (emoções) para o treinamento do ator. Todavia, anos mais tarde, ele começou a olhar cada vez mais para a ação propositada, onde a ação é intencional e não intuitiva, naquilo que denominou de ação psicofísica (uma ação tem seu propósito e ela é quem conduz ao sentimento). Em lugar de ver as emoções conduzindo a ação, Stanislavski passou a acreditar que era o contrário que ocorria: a ação propositadamente representada para chegar aos objetivos do personagem era o caminho mais direto para as emoções. Como fazer para brotar a vida física do personagem através da vida espiritual? O movimento - ação externa - serve como isca para a 
emoção. A ação passa a ser guia, estímulo primeiro para a revivecência. Pode-se dizer, conforme R ufini: "induzir a alma a acreditar, induzindo antes o corpo a viver, visto que o essencial é alcançar, de qualquer maneira, a expressão de sentimentos verdadeiros" (RUFINI, 2004, p. 9).

\section{Entorno cultural}

A pesar de considerada por alguns como uma "alegoria curricular" a educação em Arte é tradicionalmente reconhecida como meio de aquisição de conhecimentos e de "elevação cultural".

Docentes que atuam em EJA relatam com freqüência as falas dos alunos no sentido de pontuar a descoberta de novas formas de diversão e de aprendizagem pela assiduidade aos equipamentos culturais proporcionados em saídas de campo mediadas por seus professores.

Seguindo nesse sentido dos "novos olhares", o entorno cultural dos alunos se enriquece com novas possibilidades, não apenas nos momentos recreativos, mas em especial nas suas articulações sociais como um todo. É bem comum que adultos da EJA queiram ser acompanhados de seus familiares nas saídas de campo promovidas pela escola para museus, teatros ou shows.

R efletindo ainda sobre a imposição de padrões de comportamento, oferecidos em seu entorno cultural, parece que uma tomada de consciência se dá, às vezes, em três níveis e sem uma ordem exata: a percepção de que o produto artístico é essencialmente composto, que está carregado de valores e de um discurso; a percepção de que o próprio comportamento carrega um discurso e tem um aspecto de composição/associação a determinados valores (por exemplo, fazer ou evitar determinadas atitudes vistas como "coisa de homem") e a percepção desses padrões e de seus fomentadores no mundo que o cerca (os discursos e 
valores expressos nas atitudes corporais em peças publicitárias, seu glamour ou sua execração, por exemplo).

As pessoas se converteram em observadoras passivas de sua cultura, em lugar de agentes dela. O s meios de propaganda e publicidade reforçam e propiciam o condicionamento crescente do homem a imagens, padrões morais, éticos, religiosos e estéticos pré-estabelecidos. H á uma perda da individualidade, da identidade pessoal e, a partir daí, o homem só consegueencontrá-la na massa. Aspessoas tornam-se, de certaforma, personalidades padronizadas de consumo (BEN DER, 1982).

$\mathrm{N}$ a vivência teatral aparece fundamentalmente como enriquecedora a capacidade de "ler o mundo" e recriar uma realidade, ainda que ficcional. I sto está ligado ao que V iola Spolin chama de "transposição do processo de aprendizagem para a vida diária". Se no teatro um mesmo significante pode significar diversas coisas, conforme sua relação com os outros elementos que compõem a cena (por exemplo, um bastão que pode virar espada, cavalo de general ou parceira de dança), a percepção de que na "vida real" as coisas "sejam assim porque são" começa a cair por terra. Da mesma forma, o contato com o caráter dramático dos elementos da linguagem teatral propicia uma conscientização acerca das relações de poder que se estabelecem na vida. Vale lembrar que drama vem do grego e significa oposição, luta ou conflito.

O aluno passa a perceber o potencial dramático de um espaço cênico, de uma ação/reação ou de uma situação, quando consegue ver como muitas vezes traduzem jogos de poder e conflitos. A conseqüência natural é que em algum momento o sujeito passe a ter essa percepção também na sua vida.

Q uando o aluno vê as pessoas e as maneiras como elas se comportam quando juntas, quando vêa cor do céu, ouve os sons no ar, senteo chão sob seus pés e o vento em sua face, ele adquire uma visão mais ampla de seu mundo e seu desenvolvimento como ator é acelerado. 0 mundo fornece o material para o teatro, e o crescimento artístico desenvolve-se par e passo com o nosso reconhecimento e percepção do mundo e de nós mesmos dentro dele (SPOLIN , 1987, p. 13). 


\section{Considerações finais}

O cotidiano redimensionado, reapresentado, analisado e possivelmente transformado pelas experiências em educação estética que a escola pode proporcionar coloca o Teatro como atividade socializadora inquestionavelmente. A través do fomento à reflexão sobre a própria ação, seus significados e os desdobramentos que ela pode ter no seu meio social, argumenta-se em favor da educação em Arte como disciplina obrigatória também para os jovens e adultos que freqüentam os cursos na modalidade EJA.

0 teatro como linguagem artística ao exigir a compreensão do espaço, do tempo, do movimento, do jogo individual e coletivo e das convenções cênicas para a efetiva estruturação do ato teatral por parte dos alunos-atores promove a desinibição, combate a baixa auto-estima e oportuniza a consciência corporal, como expressa as diretrizes curriculares para a educação de jovens e adultos.

No caso de alunos do EJA o teatro torna-se instrumento de ressignificação social, de construção de identidade individual e coletiva, a partir do momento que propicia um espaço de reflexão e novo olhar a respeito da realidade e dos acontecimentos que o cercam.

\section{Referências}

AN TU NES, Celso. M anual de técnicas de dinâmicas de grupo, de sensibilização, de ludopedagogia. R io de J aneiro: Vozes, 1998.

BE N D ER , I vo. Teatro como possibilidade de lazer e recreação. C adernos de Teatro: tablado, R io de Janeiro, n. 72, p. 9-13, jan./mar. 1982.

BR O O K, Peter. 0 ponto demudança. R io de Janeiro: Civilização Brasileira, 1995. 
CU RY, Carlos R oberto J amil. Parecer do C NE/C EB 11/2000: diretrizes curriculares nacionais para educação dejovens e adultos. D isponível em: <http://www.portal.mec.gov.br>. Acesso em: 17 out. 2008.

PIAGET, Jean. Sobre a pedagogia: textos inéditos. São Paulo: Casa do Psicólogo, 1998.

R U FFIN I, Franco. Stanislavskij eo "teatro laboratório". R evista da FU N DARTE, M ontenegro, v. 4, 2004.

SPO L I N , V iola. I mprovisação para o teatro. São Paulo: Perspectiva, 1987. SPO L I N , V iola. 0 jogo teatral nolivro do diretor. São Paulo: Perspectiva, 2001.

STAN I SLAV SK I, Constantin. A preparação doator. R io de Janeiro: Civilização Brasileira, 1970. 